\title{
EL VALOR DE LA INFORMACIÓN PÚBLICA EN DEMOCRACIA: APORTES TEÓRICOS PARA DEFINIR UNA POLÍTICA DE REUTILIZACIÓN DE DATOS QUE IMPULSE LA ECONOMÍA DEL BIENESTAR EN HONDURAS
}

\author{
Marta Méndez Juez \\ martamendez1985@gmail.com
}

\begin{abstract}
RESUMEN
Actualmente, una de las prioridades en las agendas de los gobiernos y uno de los elementos que suscita mayor interés mediático, es la transparencia pública. Entendida como principio vertebrador de cualquier Estado Social y Democrático de Derecho, la transparencia pública acerca las instituciones a los ciudadanos y permite que éstos estén informados de lo que hacen, de cómo lo hacen y de porque qué realizan sus funciones las organizaciones públicas. La transparencia se materializa en el efectivo derecho a la información pública que tiene cualquier ciudadano, si bien puede ser ésta activa cuando las instituciones ofrecen datos a la sociedad sin requerimiento previo, o bien pasiva cuando los ciudadanos los piden con carácter previo. Sin información, sin este recurso estratégico que fluye constantemente en todos los ámbitos de la vida, no resulta posible realizar ninguna actividad personal o profesional, siendo por ello necesario que el ciudadano pueda obtener datos públicos, intercambiarlos y acceder a las fuentes que los custodian. La presente investigación muestra cómo la política de reutilización de datos públicos produce un cambio económico sustancial en la Sociedad del Conocimiento, y cómo dicho cambio sólo es posible si previamente se ha llevado a cabo una profunda reforma y modernización político-administrativa, preparando a las instituciones para que realicen un tratamiento, un intercambio y un suministro eficaz de la información pública. De este modo, la gestión inteligente de los datos públicos va a requerir la acción coordinada del Estado, de la Sociedad y del Mercado, siguiendo un modelo de gestión pública básico en la Ciencia Política y de la Administración, denominado Gobernanza Democrática. Honduras tiene un gran reto en el horizonte, pues si bien es cierto que se ha aprobado una ley de transparencia en el país, aún no se ha abordado la política de reutilización de datos, cuando ésta resulta una pieza básica en la economía del bienestar.
\end{abstract}

Palabras clave: Transparencia, Información, Reutilización; Neoinstitucionalismo; Crecimiento; Gobernanza; Honduras; 


\title{
THE VALUE OF PUBLIC INFORMATION IN DEMOCRACY: THEORETICAL CONTRIBUTIONS TO DEFINE A DATA REUSE POLICY THAT DRIVES THE ECONOMY OF WELFARE IN HONDURAS
}

Marta Méndez Judge

martamendez1985@gmail.com

\begin{abstract}
Currently, one of the priorities in the agendas of governments and one of the elements that arouses greater media interest, is public transparency. Understood as the structuring principle of any Social and Democratic Rule of Law, public transparency brings institutions closer to citizens and allows them to be informed of what they do, how they do it and what public organizations perform their functions for. Transparency is materialized in the effective right to public information that any citizen has, although it can be active when the institutions offer data to society without prior request, or passive when citizens ask for them in advance. Without information, without this strategic resource that flows constantly in all areas of life, it is not possible to carry out any personal or professional activity, being therefore necessary that the citizen can obtain public data, exchange them and access the sources that guard them. The present investigation shows how the public data reuse policy produces a substantial economic change in the Knowledge Society, and how such a change is only possible if a deep political-administrative reform and modernization has been previously carried out, preparing the institutions to carry out effective treatment, exchange and provision of public information. In this way, the intelligent management of public data will require the coordinated action of the State, the Society and the Market, following a basic public management model in Political Science and Administration, called Democratic Governance. Honduras has a great challenge on the horizon, because although it is true that a transparency law has been approved in the country, the data reuse policy has not yet been addressed, when it is a basic piece in welfare economics.
\end{abstract}

Keywords: Transparency, Information, Reuse; Neo-institutionalism; Increase; Governance; Honduras; 


\section{INTRODUCCIÓN}

Uno de los temas de mayor relevancia en esta época, una prioridad en las agendas de los ejecutivos y un elemento de debate permanente desde cualquier medio de comunicación social es la transparencia pública. Este concepto, tan manido y de latente profusión, no resulta novedoso en la historia de las civilizaciones, si bien ha cobrado una notoria relevancia en los vigentes compendios legislativos de los Estados. La transparencia es una exigencia social de primer orden y debe ser un principio democrático exponencial, que produzca cambios sustanciales en todas las esferas de la realidad social y conduzca hacia una cultura organizativa diferente, caracterizada por la apertura de los procesos, los medios y los resultados del poder público. Y eso que la democracia no es más que "el Gobierno del poder público en público” (Bobbio, 1980).

La transparencia es un principio básico del buen gobierno (Salomón, 1998; Canales, 2014) y posibilita que los ciudadanos estén al día del qué, cómo y para qué se llevan a cabo las actuaciones del poder público, que confíen en los centros de decisión política, que participen en la definición e implementación de las acciones gubernamentales, que evalúen el rendimiento de éstas y de los responsables al frente de las estructuras de poder, que crean en quiénes les dirigen y en la manera de hacerlo, que retomen la certidumbre en un escenario de continuo cambio y adaptación. La obligación de clarificar sus actuaciones, de informar sobre sus decisiones, de mostrar los resultados de sus cometidos trae consigo necesidades de simplificación organizativa, de reducción de cargas burocráticas, de reforma y modernización públicas. Es labor de las instituciones mejorar el servicio que prestan al ciudadano, generando en ello confianza y apertura.

Por todo ello, puede afirmarse que la transparencia

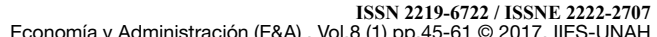
El Valor de la Información Pública en Democracia: Apprtes Té́ricos para Definir una Política de Reutilización de Datos que Impulse la Economía del Bienestar en Honduras

MARTA MÉNDEZ JUEZ

alcanza su máxima expresión en el derecho a la información pública dequedebedisfrutarcualquier persona y que viene reconocido en el artículo 74 de la vigente Constitución de la República de Honduras de 1983. Y es que la información se ha convertido en la materia prima básica con la que transformar otros productos elaborados. Sin información, sin este recurso dinámico que fluye constantemente en todos los ámbitos de la vida, no resulta posible realizar ninguna actividad personal o profesional, siendo para ello necesario obtener datos, poder intercambiamos y acceder a las fuentes que los custodian. La información se ha convertido en la piedra angular sobre la que se asienta nuestra vida individual y colectiva y sentimos la necesidad constante de conocer para decidir, para emprender, para participar, para fiscalizar, para trabajar, para desarrollar.

La materialización del referido derecho a la información puede producirse desde dos vías diferentes: de forma pasiva, cuando el ciudadano pide a las instituciones que le faciliten datos sobre determinadas materias, o de forma activa, cuando son éstas últimas las que suministran a la sociedad la información antes de que se la requieran. Ambas modalidades van a ser tratadas en esta investigación, si bien la segunda de ellas -también denominada transparencia activa-, será abordada con mayor detenimiento por su reciente incorporación a la vida jurídica, sobre todo tras la entrada en vigor del Decreto $N^{\circ} 1702006$ por el que se aprueba la Ley de Transparencia y Acceso a la Información Pública de Honduras, así como por su Reglamento de desarrollo del año 2008.

En este sentido, las instituciones públicas cumplen un papel relevante en la sociedad tecnológica, pues tiene la misión de hacer viable el derecho a la información, ya que son quienes más datos acapara y quienes mejor puede tratarles y exponerles para el conocimiento general de la sociedad. Esta finalidad le circunscribe a la realidad y les obliga a informar de todo cuanto 
acontece en su interior, de las decisiones que adopta, de las actuaciones que realiza, en definitiva, del servicio que presta al ciudadano, en lo que hemos venido a denominar función informadora institucional.

Pero dando un paso más allá, se observa cómo la reutilización de la información pública es una política pública que se está expandiéndose de forma acelerada el entorno. El uso de datos público para finalidades diferentes de las que motivaron su recopilación inicial puede ser relevante para la creación de soluciones tecnológicas que generen un importante beneficio a la sociedad y a la economía. Recientes estudios muestran unos resultados muy favorecedores para la economía digital de los activos de información pública, la creación de empleo y el crecimiento y la competitividad empresarial, sin embargo, el gobierno de Honduras todavía no ha regulado tal cuestión.

De este modo, se observa cómo la transparencia pública en general, y el derecho a la información pública en particular, determinan la posibilidad de cambio institucional y, lo que es más relevante, condicionan la política de acceso a los datos públicos, y con ella, la política de reutilización de éstos. Un tratamiento correcto de los activos de información pública asegura un mejor servicio al ciudadano y un funcionamiento eficaz de las estructuras político-administrativas, logrando una adecuada gestión de los datos desde el origen. El principal valor de la información es su posterior transformación en conocimiento, por lo que resulta de vital importancia poder encontrar, en tiempo y forma, cuantos datos públicos puedan ser mostrados a la sociedad.

Como se señalará posteriormente y partiendo de una perspectiva politológica neoinstitucional, se considera que, en materia informativa, no puede producirse un cambio económico en el uso de datos públicos, si previamente no se han preparado las estructuras organizativas para realizar un tratamiento y publicidad eficaz de la información pública. Si se considera a este recurso como estratégico, el uso público o privado que se produzca de la información que tienen las instituciones, dependerá de cómo se recoja, almacene, trate y disponga ésta. En resumidas cuentas, deberán tomarse en consideración una serie de cambios institucionales para poder emprender un cambio económico viable, sostenible, que mejore el bienestar de los ciudadanos y que no condicione el cumplimiento eficaz del interés general.

Esta hipótesis de partida parte de la premisa de que el éxito de la política de reutilización de datos públicos -el cambio económico-, dependerá de cómo se lleven a cabo las relaciones interadministrativas en materia informativa -el cambio institucional-. Dicho de otro modo, el contexto institucional va a determinar el contexto económico, pues en estructuras organizativas donde exista interacción institucional, adaptación constante al entorno, servicios telemáticos interoperables y fiables y seguridad jurídica, será posible la reutilización de la información generada por el sector público, con vistas a que las personas físicas y jurídicas, públicas o privadas, tengan acceso a un alto porcentaje de datos, que sean usados para finalidades diferentes de las que motivaron su recopilación. Sin un sistema político eficaz, no puede generarse un sistema económico equilibrado. Sin un cambio institucional profundo, es imposible que acontezca un cambio económico trascendental, que haga viable el derecho a saber del ciudadano desde la obligación pública de suministrar datos, y preocupe la inversión y el rendimiento económico a largo plazo, más que el beneficio directo que se obtenga de tal prestación.

\section{MARCO TEÓRICO}

En este caso, se partió de la siguiente hipótesis: 
El éxito de la política de reutilización de la información pública va a depender de cómo se lleven a cabo las relaciones interadministrativas. Dicho de otro modo, el contexto institucional va a determinar el contexto económico, pues en aquellas estructuras organizativas donde exista: a) interacción institucional; b) adaptación constante al entorno; c) servicios telemáticos interoperables y fiables; y d) seguridad jurídica, será posible la reutilización informativa para que los ciudadanos tengan acceso a un alto porcentaje de datos públicos, que sean usados para finalidades diferentes de las que motivaron su recopilación, así, sólo si se producen estos cambios en el marco institucional podrán, desarrollarse cambios en el marco económico.

En este análisis, se llega a la conclusión de que el cambio económico es la consecución de una política de reutilización de la información pública efectiva-, viene determinado por el cambio institucional $-\mathrm{o}$, lo que es lo mismo, un avance hacia la cultura de transparencia del poder público-- El escenario de mejora no resulta del todo fácil para las organizaciones públicas, pero puede generar un espacio público como "ámbito legítimo para canalizar la participación ciudadana y ejercer el derecho colectivo a la libertad de expresión" (Mejía Rivera y Menjívar Rosales, 2015:28).

En base a lo anterior, tal análisis se adaptará a los postulados propios del enfoque neoinstitucional de la ciencia política (Butler, 1958; Leftwich, 1984; Gunnarsson, 1991; Lowndes, 2013), y se entiende que por institución las reglas, las normas, las costumbres y las relaciones que constituyen el cimiento de las relaciones de intercambio en la sociedad. Extrapolando este enfoque politológico al motivo de la presente investigación, uno de los autores más destacados en la materia, Douglas North (1993), señala lo siguiente: "el cambio tecnológico y el cambio institucional son las claves básicas de la evolución social y económica" (p. 135), En la misma línea, el citado autor afirma que "la politica crea y hace cumplir las reglas económicas" (p. 142), y que "las reglas políticas situadas en su lugar, conllevan a reglas económicas" (p. 69).

Desde el enfoque neoinstitucional, se entiende a las instituciones como las reglas formales e informales que, a modo de limitaciones ideadas por el ser humano, reducen la incertidumbre y hacen posible la interacción social. Será, sin duda, la información que manejen éstas el motor para su mejora y la razón de ser de toda institución democrática, pues dicha información facilita el conocimiento del medio en un contexto impredecible, y minora el riesgo de adaptación a la realidad e induce al cambio institucional y social. Sólo se puede cambiar lo que conoce y mejorar aquello que nos es revelado.

El nuevo institucionalismo incide, ante todo, en la idea de que las organizaciones consideradas desde todos los ámbitos posibles han crecido, se han complejizado y se muestran menos eficaces en la actualidad, para lo cual acuden a técnicas modernizadoras que las sitúen y reformulen en la sociedad presente.

Por tanto, el neoinstitucionalismo defiende: a) que la mejor manera de entender los procesos políticos es de una forma global y no como una mera consecuencia agregada de los comportamientos individuales de las personas; $b$ ) que las acciones son el resultado de elecciones basadas en la confluencia del interés general y no en el simple cálculo de intereses individuales; c) que los acontecimientos políticos son el resultado de múltiples factores y no sólo consecuencia de las decisiones calculadas y deliberadas de los individuos; y d) que las instituciones evolucionan a través de procesos históricos deficientes, sin que exista una única solución de adaptación al ambiente; y que los elementos centrales de la vida política son las instituciones y no los procesos de 
adopción de decisiones y de distribución de los recursos (Johnson, 1975).

Las instituciones determinan, ordenan, modifican $\mathrm{y}$ hacen posible las elecciones individuales que, en ningún caso, gozan de absoluta racionalidad. La economía no puede hacerse eco de las sutilezas de un análisis más integral que requieren las organizaciones, que más que preocuparse por el individuo en exclusiva, lo hace de éste en colectividad. No resulta válida la posición tomada desde la teoría racional en lo que respecta a las decisiones ciudadanas pues, entre otros motivos, los ciudadanos no disponen de información completa con la que elegir una de entre las posibles alternativas que se les pueden presentar. Y profundizando más en esta idea, si las administraciones públicas dispusieran cuantos datos obrasen en su poder, las decisiones que pudiesen adoptar los ciudadanos serían más cualificadas pero insuficientes para saber optar por alguna de las alternativas que maximicen su beneficio personal.

Hay que incidir en el hecho que el valor en la disposición de información por parte de los poderes públicos no es una prebenda al ciudadano para ayudarle de forma individual, sino que, sobre todo, es una labor básica y necesaria en cualquier sistema democrático que ayuda al desarrollo del ser humano en colectividad, en la adopción de decisiones colectivas. Así, el poder público que ejercen las instituciones sólo es válido si se conoce por el ciudadano, si las instituciones iluminan sus actuaciones cultivando la transparencia, porque es a él al que le corresponde en colectividad.

Así mismo, cabe señalar que las instituciones actúan de manera autónoma respecto del resto de organizaciones sociales, aunque ello no signifique que deban funcionar al margen de éstas últimas para la consecución de sus objetivos y para lograr la tan ansiada cohesión social. Es evidente que existe una interdependencia entre todas las instituciones, pero se reitera la posición de superioridad de las organizaciones políticas sobre las demás.

Por eso, no se puede supeditar el comportamiento de las instituciones políticas al del resto de organizaciones -incluidas las económicas-, pues la relación de causalidad se construye, precisamente, a la inversa. El marco institucional es la guía de referencia, la que establece las normas, los procedimientos, los valores, la cultura organizativa, componentes esto últimos que son el cimiento que unifica la acción social, que aminoran la incertidumbre que produce el cambio, que equilibran y ordenan la convivencia pacífica de los ciudadanos. $\mathrm{Y}$ estas funciones las ejerce dicho marco en exclusividad, por lo que, inevitablemente, trasciende del resto de las organizaciones, al situarse como el modelo referencial de todas ellas.

Por la razón señalada precedentemente, consideramos que la información pública no otorga poder a las instituciones, que ya lo tienen por la función social que realizan y porque los propios ciudadanos las han investido de él. La información pública no les pertenece, no puede permanecer estancada en los archivos y los registros y supeditada a los férreos controles de su conservación y de su custodia.

Esto sólo puede ser un síntoma de debilidad institucional, de miedo a que se sepa lo que esconden las organizaciones, en definitiva, de desconfianza social generalizada. El poder reutilizar los datos que las organizaciones públicas generan, no supone una intromisión en su funcionamiento o una vulnerabilidad en la planificación de sus objetivos, sino que, por el contrario, simplemente es un deber que éstas tienen para con la sociedad.

Otra cosa es que, para mantener el orden social, el marco institucional establezca una serie de requisitos o de condicionantes para que la 
reutilización se produzca, pero siempre bajo la premisa de que el interés colectivo, el equilibrio social, el orden institucional es, ante todo, lo que debe imperar en las Administraciones Públicas.

Por tanto, la ciencia política necesita, simplificara la interpretación de la conducta individual maximizadora de preferencias para poder comprender el comportamiento de los actores en colectividad; para ello, es imprescindible que se nutra de la capacidad empírica y generalizable que ofrecen otras disciplinas, para poder predecir comportamientos sociales en determinadas situaciones y con ello, disminuir el conflicto social. Los costes transaccionales analizados anteriormente informan de ello, y nos ofrecen una visión empírica de la importancia que tienen las instituciones a la hora de reducir el coste o mitigar el riesgo en el intercambio de determinados bienes sociales. Por ello, si las administraciones públicas mejoran su funcionamiento interno, si son capaces de optimizar los recursos que poseen, si normativizan adecuadamente sus procesos, si consiguen fomentar las relaciones formales e informales que acontecen en su interior en materia informativa conseguirán, no sólo reducir el coste del intercambio de datos produciendo un beneficio directo a la sociedad, sino también logrará modernizarse a nivel interno para cumplir mejor con sus objetivos.

De acuerdo con lo anterior, puede afirmarse que las instituciones son capaces de adaptarse y de reformarse y, con ello influir en los procesos de cambio de las organizaciones económicas, pues aprenden de la experiencia y del bagaje acumulado durante muchos años de existencia; y retomando los postulados del clásico Institucionalismo cuando hacía hincapié en el claro influjo que ejercía sobre él otras disciplinas académicas, especialmente la historia. Cuando se analizan las organizaciones, se debe ser muy consciente que éstas no han surgido del vacío más absoluto o por generación espontánea, sino que responden a la larga y continuada influencia que, sobre ellas, ha ejercido el devenir de los tiempos. No puede modernizarse partiendo de cero, con técnicas miméticas alejadas del contexto en el que se circunscriben las instituciones, pues los ciudadanos no las sentirían como propias y no entenderían su existencia y las capacidades que despliegan para lograr la cohesión social.

La modernización es un proceso difícil, largo, y muchas veces conflictivo. Las instituciones se desarrollan históricamente para poder alcanzar cierta estabilidad en el tiempo, una estructuración organizativa y una formalidad en sus procesos internos y en los modos de relacionarse entre sí y con otras; y en ello reside su fortaleza y legitimidad, en su capacidad de adaptación al medio en el curso de los tiempos y en guardar la estabilidad del sistema en una situación de inestabilidad del medio constante.

Al respecto, Aranguren Gonzalo (2005), ofrece una explicación que comparto fehacientemente sobre la necesidad del cambio institucional, mostrando fiel reflejo de las demandas ciudadanas y observando cómo, la realidad de las organizaciones no debe permanecer tampoco inmutable a la realidad social en su conjunto: " $e l$ mundo no está acabado; está siendo, y nuestro modo de estar en el mundo es, necesariamente, transformándolo".

El enfoque neoinstitucionalista aporta la idea de que la mejor manera de entender los procesos políticos es asumir la importancia de las preferencias colectivas y no la consecuencia agregada de los comportamientos individuales, y que los acontecimientos políticos son el resultado de múltiples factores y de la evolución que las organizaciones han experimentado a lo largo de la historia, más allá de los simples e ineficientes enfoques legales $\mathrm{y}$ formalistas. El nuevo institucionalismo enriquece pues, sin duda, esta investigación, ya que asume el estudio de las 
administraciones públicas desde la perspectiva del poder público, por lo que no sólo hay que estudiar qué son las instituciones, sino también cómo éstas se manifiestan en relación con otras organizaciones sociales.

Se entiende, que las instituciones políticas, además de constituir restricciones a la elección de los individuos, también crean instrumentos que motivan sus actuaciones. En el objeto de esta investigación, tal afirmación resulta evidente, pues de cómo se gestionen, se conserven y se difundan los datos a nivel interadministrativo, dependerá la correcta implantación de la política de reutilización de la información pública en España. Las instituciones no siempre limitan y coartan la libertad ciudadana, sino que también facilitan y motivan la participación. Y, en el referido sentido las instituciones tienen que estar preparadas para proporcionar, en cualquier momento, una información de calidad, correcta, comprensible, transparente, fiable, segura, ágil, automática, en tiempo real y ajustada a las demandas de los ciudadanos.

Desde el año 2006, Honduras cuenta con una ley específica de transparencia, cuya finalidad reside en promover el ejercicio del derecho de toda persona al acceso a la información pública para el fortalecimiento del estado de derecho y la consolidación de la democracia mediante la participación ciudadana (artículo No. 1). De igual modo, la normativa ofrece una definición de información pública muy extensa y enriquecida en su artículo No. 3.5, considerando a ésta en el sentido más laxo del término, e instando a las instituciones obligadas de los tres poderes del Estado a facilitar datos al ciudadano. Tan sólo una salvedad cabe hacer a la definición de información pública que incluye la ley, y es que el artículo mencionado señala tal obligación de informar sin importar la fuente o la fecha de elaboración de la misma. Se considera esta afirmación desacertada, por cuanto es básico requerir a toda la información pública la fuente de la que proviene y su mayor actualización en el tiempo.

Otra de las grandes aportaciones del Decreto $\mathrm{n}^{\mathrm{o}}$ 170-2006 para favorecer el cambio institucional que permita, a su vez, un cambio económico con la política de reutilización de datos, deriva del contenido del artículo 12 de la normativa, al crear un sistema nacional de información pública cuyo propósito es integrar, sistematizar, publicar y dar acceso a la información pública por medio de todos los subsistemas de información existentes, los cuales deberán integrarse en formatos uniformes de acuerdo a las normas y procedimientos establecidos en él. Honduras cuenta con más de 80 portales web de transparencia, los cuales muestran muchas deficiencias en cuanto a su funcionamiento y en cuanto al cumplimiento de las obligaciones legales de publicidad informativa. Y aunque todos ellos guardan cierta sistematicidad en el diseño, lo cierto es que cada uno refleja sus datos de una manera y éstos siempre son excesivamente escasos y desfasados a vista del ciudadano. A su vez, aunque el Instituto de Acceso a la Información Pública facilita desde su Sitio Web el acceso al denominado Portal Único de Transparencia, esta aplicación deja mucho que desear y no responde a la voluntad primera del legislador de lograr el mayor conocimiento de los ciudadanos sobre la acción pública para participar en la toma de decisiones y confiar en la función gubernamental.

Si bien toda libertad conlleva un límite y toda obligación, una justificación, las restricciones que el legislador dispone en el artículo 16 para acceder a la información pública son demasiado difusas y ambiguas, impidiendo la mayor difusión posible de los datos públicos. Los límites, pues, son muy genéricos y otorgan amplio margen de maniobra a los poderes públicos para restringir la publicidad activa y pasiva de información. El mismo efecto produce lo normado en el artículo 
siguiente, relativo a la información reservada por parte del Estado.

En base a lo anterior, se observa resumidamente algunas disfuncionalidades que ofrece la ley y que condicionan el correcto desarrollo, no sólo de una futura política de reutilización de datos, sino también de la propia política de transparencia. La clave para la mejora está en fortalecer los sistemas de información de las organizaciones, pues éstos permiten a las instituciones cumplir con sus deberes de tratamiento, de intercambio $\mathrm{y}$ de difusión de datos públicos. Una correcta gestión de los activos de información puede mejorar el rendimiento de la administración y hacer que controle y publicite el mayor volumen de datos posible. No se trata de que tal función informadora pase a ser una más de todas las que ya cumple, sino que esta obligación vaya permeando su actividad diaria hasta llegar a considerarse habitual y natural en las instituciones. El reto no es sencillo, pues exige grandes dosis de voluntad política y de inversión financiera, pero los beneficios que pueden extraerse de dicha práctica pueden ser exponenciales.

La adaptación tecnológica de los equipos informáticos, la formación y actualización de los servidores públicos y la inversión permanente en recursos que reduzcan la incertidumbre de un contexto mundial cada vez más dinámico e interconectado, son claves si queremos gestionar correctamente el recurso más importante que poseen las instituciones, esto es, la información. En tal sentido, se requiere introducir mejoras en la ley de transparencia de Honduras -y también en su reglamento de desarrollo- pero, sobre todo, es urgente que se cumpla a lo que la norma obliga; asimismo, deben aplicarse esquemas básicos de seguridad y de interoperabilidad que consigan desarrollar sistemas de información más dinámicos y actualizados.

Desde la obligación institucional a la publicidad informativa, es preciso señalar que el principio de colaboración fomenta las relaciones interinstitucionales, y puede ayudar a superar las vicisitudes que muestra un escenario de descentralización política y funcional, proclive a los desencuentros.

La interoperabilidad es uno de los grandes retos de futuro, e implica la acción conjugada de todos los centros de poder político para lograr su correcta aplicación. Sólo desde ella, se puede conseguir una correcta transferencia de recursos, utilizando sistemáticas comunes, reglas procedimentales y aplicaciones homogéneas para cumplir con tal función. Un reto importante en Honduras sería lograr que todos y cada uno de los portales de transparencia de las instituciones fueran homogéneos, cumplieran con sus obligaciones legales de difusión activa de datos, fueran reduciéndose en número, pero no en contenido, $\mathrm{y}$ lograran verter toda su información interoperable en el Portal de Transparencia Unificado del país, para favorecer con ello su tratamiento, intercambio y publicidad entre instituciones y de éstas a los ciudadanos.

Tener un gran almacén de información pública supone un cambio institucional de primer orden, que puede ayudar a la economía digital de datos. Pero la información pública, tal y como parece desprenderse del artículo No. 13 de la ley de transparencia de Honduras, no sólo incluye la información de servicio, esto es, la información administrativa a través de la cual los ciudadanos pueden acceder al conocimiento de sus derechos y obligaciones y a la utilización de los bienes y servicios públicos. Por eso, sólo si se cumplen los siguientes requisitos, puede hablarse de información pública (Ramos Simón, Mendo Carmona et al., 2009:46):

a) Estar bien recopilada, con series temporales muy amplias que resultan de gran utilidad en los análisis. 
El Valor de la Información Pública en Democracia:

Aportes Teóricos para Definir una Política de Reutilización

de Datos que Impulse la Economía del Bienestar en Honduras

b) Ser recolectada por guardianes neutrales y que los criterios de recogida de esa información sean públicos.

c) Gozar de la presunción de fiabilidad ya que, en muchos casos, esa confianza queda reforzada porque los propios suministradores son los principales interesados en ello (obtención de un status).

d) Mantener su continuidad, evitando la ruptura de la serie porque puede convertirse en un asunto de controversia pública.

e) Digitalizarla, ya que esto potencia las posibilidades de su explotación y hace más visibles las diferencias entre instituciones y las prácticas de mejora entre ellas.

Así, el reto de los gobiernos debe consistir en seguir fomentando un uso común y coordinado de recursos, invirtiendo medios y personal en el tratamiento y en la gestión de la información, y normalizando pautas de trabajo colectivas. Las estructuras institucionales deber mostrarse proclives a las interconexiones y facilitar todo cuanto esté en su mano, para que el cambio tecnológico y el cambio institucional vayan de la mano en el desarrollo de la sociedad del conocimiento. Estas mejoras, no sólo pueden beneficiar a los ciudadanos en el front office de la administración pública -en su nivel externo-, sino también a las propias estructuras de su back o ffice -en su nivel interno-. Desde la obligación al suministro de datos de la función informadora institucional, es preciso destacar que convergen, en la actualidad varios espacios de difusión de información pública, unos tradicionales y otros más avanzados. Se considera que el medio electrónico debe ser el que prevalezca, para lo cual es preciso adaptar los formatos en que se encuentran la información pública a las nuevas tecnologías de forma gradual, y sin que ello suponga una discriminación o brecha social para aquellos a quienes les cueste más adaptarse al cambio.

Todo lo que poseen las instituciones no es todo lo que muestran y además, la información accesible sólo constituye un pequeño reducto. Por ello, parece obvio pensar que hasta que no vaya derribándose el muro que separa la información pública que poseen las instituciones de aquella que muestran al ciudadano, más difícil será que tal información pueda ser reutilizable para la sociedad. Es un reto para todos implementar cambios en las dimensiones sociotécnica, político-cultural y de mejora y control en las instituciones, que consigan iluminar el poder público $\mathrm{y}$, por ende, facilitar el progreso social y económico.

La reutilización de la información pública es una oportunidad de futuro para que la sociedad y el mercado se nutran de los datos que generan, tratan y almacenan las instituciones, para elaborar otros productos competitivos. Sin embargo, la reutilización suele estar sujeta a un gravamen económico por parte del Estado, hasta el punto en el que: "la reutilización es más un (info) negocio que democracia, sin perjuicio de que los datos abiertos reutilizables puedan servir para dar mejor información sobre el funcionamiento y los gastos del poder público (Cotino Hueso (2014:51). Tal visión no es del todo desacertada por lo que, en opinión, sería necesario invertir la dinámica para que la reutilización de información sea, ante todo, un elemento democrático y no únicamente un componente del mercado. Si el gobierno de Honduras decidiese implementar esta política pública, tendría que ser bajo el compromiso de no acrecentar el erario a costa de mermar las ya de por sí fustigadas economías domésticas. 


\section{RESULTADOS}

La reutilización de la información generada por las instituciones públicas -en especial, la administración-, constituye una de las actividades de mayor impacto en nuestros días, ya que es una fuente de primer orden en el desarrollo social y económico de cualquier Estado. Puesto que esta política de reutilización aún no ha sido desarrollada legislativamente en Honduras y, por tanto, no se cuenta con evidencia empírica al respecto, se incluirá en este apartado algunos datos socioeconómicos que ha generado esta medida en Europa y en España. Así, cumpliendo con lo establecido en la Directiva 2003/98/CE, relativa a la reutilización de la información del sector público, el legislador estatal español ha aprobado la Ley $37 / 2007$, de 16 de noviembre ${ }^{4}$, en la que se define reutilización como: "el uso de documentos que obran en poder de las Administraciones y organismos del Sector Público, por personas fisicas o jurídicas, con fines comerciales o no comerciales, siempre que dicho uso no constituya una actividad administrativa pública"'.

Como se describió con anterioridad, las instituciones públicas realizan una labor de vital importancia en este sentido, ya que son quienes crean, recogen, tratan, almacenan y difunden información a mayor escala, la cual tiene gran interés para dos tipos de actores: para las propias entidades públicas, al crear nodos de interoperabilidad administrativa en los que las organizaciones intercambian los datos que poseen y ofrecen así servicios al ciudadano de más calidad; y para las entidades privadas, al optimizar recursos y facilitar la actividad profesional de éstas. La reutilización de la información pública crea valor a los datos recogidos para una finalidad concreta, multiplicando su funcionalidad para la consecución de otros intereses públicos y también privados.

\footnotetext{
4 La cual se desarrolla por el Real Decreto 1495/2011, de 24 de octubre.

5 Se ha transcrito el contenido literal del artículo 3.1 de la Ley que tiene por objeto: "la regulación básica del regimen juridico aplicable a la reutilzación de los documentos (según el artículo 1 de ésta).
}

Como recogió el estudio MEPSIR ${ }^{6}$, el valor económico del mercado de la reutilización, calculado según la cifra de negocio de las actividades generadas en este ámbito $-\mathrm{y}$ a la que se le resta el coste de adquisición de dicha información-, oscila entre los diez mil y los cuarenta y ocho mil millones de euros, lo que origina un valor medio de unos veintisiete mil millones de euros dicho mercado en la Unión Europea. Por resumirlo de alguna manera, el valor que tiene en el mercado comunitario la reutilización de la información pública fluctúa en torno al uno por ciento del total de su Producto Interior Bruto.

En el caso concreto de España, el citado estudio prevé que la reutilización traiga consigo la creación de un nuevo sector productivo basado en dicha finalidad reutilizadora, que puede generar más de dos mil cuatrocientos millones de euros y cuarenta y cinco mil empleos a diez años vista. Estas cifras han sido corroboradas por estudios posteriores de consultorías privadas, las cuales han analizado cómo la información pública es un activo de insuperable valor para cualquier negocio ${ }^{7}$ y el motor para la actividad económica de cualquier país avanzado.

En el 2012 se elaboró, de carácter anual, Estudios de caracterización del sector infomedial en España. El propio Estudio ${ }^{8}$ se definió como Sector Infomedial al conjunto de empresas -tanto a las que se han creado con esta finalidad como las que

6 "Measuring European Public Sector Information" (MENSPIR), es un estudio encargado

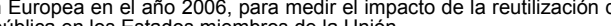
en los Estados miembros de la Unión.

7 Un ejemplo en este sentido lo constituye en informe elaborado por la empresa Rooters en España en mayo de 2011, bajo el título Reutilización de información pública y privada en España. Avance de situación para agentes públicos y privados. Una o un caso concreto de una compañía minera canadiense (GoldCorp) la cual decidió liberar los datos de sus yacimientos y explotaciones, a la vez que estableció incentivos económicos para sus diferentes usos. De esta forma, algunos expertos externos pudieron identificar las mejores vias de prospección de yacimientos y ello significó la salvación de la compañia, que incluso multiplicó su valor de mercado un veinticinco por ciento en menos de doce años.

8 Dichos Estudios anuales son elaborados por la Secretaría de Estado de Administraciones Públicas del Ministerio de Hacienda y Administraciones Públicas, por la Secretaría de Estado de Telecomunicaciones y para la Sociedad de la Información del Ministerio de Industria, Energía yurismo y por el Observatorio Nacional de las Telecomunicaciones y la Sociedad de la lnormación, con el asesoramiento y desarrollo del trabajo de campo y el análisis de los resultados. El último Estudio se ha elaborado en el año 2012 
sólo posean un área específica dedicada a tal fin, si ser éste su principal negocio-, que generación productos y servicios para su comercialización a terceros a partir de la información que recogen del Sector Público.

Las cifras extraídas del citado Estudio ${ }^{9}$ hablan por sí solas:

a) Se identifico un universo de ciento cincuenta empresas infomediarias en España, de las que el setenta por ciento señalan que la actividad reutilizadora ha crecido o, al menos, se ha mantenido respecto de las cifras del año pasado.

b) Las ramas de actividad ${ }^{10}$ más prolíficas en materia de reutilización de la información son la información geográfica y meteorológica y de negocios o economía. Así, la información geográfica y meteorológica representa el cincuenta y uno por ciento del total del valor económico de la información del Sector Público, seguida de la información económica (que representa el diecisiete por ciento) y la información de negocios (que representa el catorce por ciento del total).

c) Un tercio de las empresas infomediarias tienen clientes fuera de España, por lo que esta actividad les ayuda en su actividad expansionista.

9 Se refiere a las cifras que se presentan en el último Estudio de Caracterización del Sector Infomediario en España, publicado en el año 2012.

10 Los cuatro ámbitos de información principales que recoge el citado Estudio son Eeográfical Cartográfica; Información sobre Negocios Ello no significa que estos sodemográfical Estadistica; e Información Jurídico-Lega que comparten y utilizan información de diversos ámbitos para generar servicios en los que combinan múltiples informaciones para dar un mayor valor añadido a su actividad. d) Casi un $(30 \%)$ de las empresas generaran aplicaciones para dispositivos móviles. Existe tal demanda de algunos servicios que utilizan la información pública como los servicios personales de navegación-, que sus ventas se han triplicado.

e) $\operatorname{El}(98 \%)$ de las empresas reutilizadoras utilizan el formato electrónico para la distribución de sus productos o servicios.

f) La reutilización de la información pública en España adquirió un volumen de negocio de entre trescientos treinta y quinientos millones de euros, lo que, en términos concretos, supone entre el cuarenta y el cuarenta y cinco por ciento de la actividad total de las empresas infomediarias en el país.

g) La masa laboral asociada a la actividad infomediaria se sitúa en cerca de cuatro mil empleos.

\section{DISCUSIÓN}

Como se describió epígrafes anteriores, la información pública constituye una pieza esencial para la continuidad de la vida democrática, pues legitima la acción del poder público ejercido desde las instituciones y controla la forma que la que éste se materializa, responsabilizando a los representantes políticos de las decisiones que adoptan. Por ello, resulta imprescindible y necesario que dicha información esté al alcance de los ciudadanos, para que puedan entender la finalidad colectiva que ejercen los poderes públicos, que no es otra que la cohesión social en un entorno complejo y cambiante. 
Si el objeto de esta investigación lo constituye lo que el legislador ha venido en denominar "reutilización" de la información generada desde el sector público, el foco de atención se va a situar, precisamente, en el marco institucional en el que se genera, conserva, intercambia y difunde, esto es, en las organizaciones públicas. Pero si se profundiza en el estudio de las organizaciones y de las relaciones que entre ellas se producen, es del todo preciso que se resalte una aproximación al estudio desde el análisis de su estructura (Vallés Casadevall, 2000:45), desde la Policy, aclarando que ésta -la organización-, no debe confundirse como una maquinaria inamovible de dominación social, sino como un organismo viviente, relacional, formal e informal, que activa su estructura en su necesidad funcional de adaptación al medio, al que aporta algo que justifica su subsistencia.

Esto es lo que ha denominado dimensión política de las instituciones $\mathrm{y}$, especialmente, conceptualizado como administración democrática, al ser ésta quien más influye en el tratamiento y la difusión informacional. Y lo que se destaca en la política de reutilización de datos son, precisamente, las interacciones múltiples que componen la red relacional y la información que intercambian los actores, teniendo en cuenta la "cualidad" de la relación que mantienen, así como los "medios y modos" mediante los que se relacionan (Ramos Muslera, 2015:143).

Por ello, las instituciones públicas, si desean cumplir con el interés común para el que fueron creadas y desde el cual se legitiman, deben adaptar, de manera homogénea, su marco jurídico, organizativo y técnico informacional a los nuevos requerimientos sociales, valiéndose de las ventajas que para tal fin ofrece la sociedad tecnológica. Con ello, estarán en disposición de ofrecer servicios públicos de calidad, de gestionar sus recursos de manera eficaz y con el propósito de un fin común.
Esta tarea no resulta nada sencilla, máxime se tiene presente que el Estado se concibe hoy en día: "como complejo, y compuesto por una constelación plural y diversa de instituciones políticas y administrativas, que actúan en continua y profunda interrelación" (Canales Aliende, 2002:25). De esta manera, afrontar el estudio de las relaciones organizativas no resulta nada sencillo, se atenderá a la complejidad que ofrecen los sistemas político-administrativos, donde conviven la unidad y la diversidad, la descentralización y la centralidad, la autonomía y la dependencia, la exclusividad y la colaboración competencial.

Esta idea antedicha, se resume con claridad a través de un término muy frecuentado en el análisis comparado, cual es el de policentrismo ${ }^{11}$, para hacer alusión a que la importancia de las organizaciones públicas no reside en lo que son o en lo que hacen, sino en la finalidad que cumplen, donde lo relevante no es su ámbito de actuación, la actividad que realizan o las competencias que desarrollan, sino en el para qué del servicio que prestan al ciudadano, en la aportación que las organizaciones hagan al sistema democrático.

De la complejidad aludida se perciben, a simple vista, ciertos problemas a los que se intenta ofrecer respuesta: a) técnicos, pues los sistemas operativos del sector público no son, muchas veces, compatibles entre sí, por lo que es más difícil poder desarrollar nodos de interoperabilidad y transmitir información para que pueda ser reutilizada; b) normativos, pues no existe una clara regulación legal de esta materia $\mathrm{y}$, además, es prolija la legislación sectorial que se ve afectada o que influye directamente en la política de la reutilización; procedimentales, pues las rutinas administrativas resultan excesivamente rígidas y garantistas $\mathrm{y}$

\footnotetext{
11 Bajo dicho concepto (Ostrom, 1974), se defiende la idea de que en un país donde existe una multiplicidad de jurisdicciones politico-administrativas, solo se puede funcionar con eficacia si se establecen relaciones institucionales fluidas y constantes entre los diferentes organismos que las componen los cuales, investidos de poder público, formulan reglas, las ejecutan y las supetvisan. Asi, no existe una autoridad entre las múltiples estructuras organizativas.
} 
ello dificulta el acercamiento interinstitucional y de éstos con terceros actores para la fluidez y la reutilización de datos públicos; y c) estructurales, pues la escasa comunicación, cooperación y colaboración en las instituciones dificulta su actividad diaria a nivel interno y externo.

Dicho lo cual, tampoco debe perderse de vista el principio de lealtad institucional, pues las administraciones públicas deben hacer un esfuerzo especial y valorar el impacto que sus actuaciones pueden provocar en el resto de organizaciones, respetando el ejercicio legítimo de las competencias que cada institución tenga atribuidas y ponderando la totalidad de los intereses públicos implicados. Por eso es $\tan$ necesario que intercambien entre ellas la información que adquieren y conservan en relación a la actividad que desarrollan, porque de ello depende su adaptación al medio y el cumplimiento de su finalidad de cohesión social.

Se considera que, si existe un tema primordial al que debe darse cabida en el presente estudio, éste es el de las relaciones interadministrativas. Siguiendo con la idea, Villoria Mendieta (2010:91), se reafirma la necesidad de coordinar la actuación de los ejecutivos, entendida ésta desde tres niveles diferentes: a) evitando contradicciones entre ellos; b) buscando una cooperación entre ellos, manteniendo cada cual sus objetivos; y c) compartiendo finalidades comunes. Este último nivel de coordinación, en de compartir finalidades, es el más relevante para el presente estudio.

Así pues, el acceso a los activos de información pública cumple una clara función democrática, por la difusión de ésta a los ciudadanos para el cumplimiento de superiores derechos, libertades y principios. Tal y como afirma Cobacho López (2014:158): "las informaciones que obtenga empleen y generen los órganos públicos en el ejercicio de cualquiera de sus funciones, con independencia de su contenido, pertenecen, por supuesto de forma mediata, al pueblo soberano".

Si bien la gestión de la información tiene más que ver con la transparencia y aglutina todas las fases del ciclo de vida del documento y persigue objetivos tales como la configuración normalizada de ésta, su disponibilidad, su organización, su control y su uso, cuando hablamos de gestión del conocimiento, destacamos que la información pública es el motor que multiplica las capacidades intelectivas de los ciudadanos, pues genera una sintonía entre las necesidades de información de una persona y las posibilidades informativas de otra, que nos permite explotar cooperativamente los recursos de conocimiento basados en el capital intelectual, generando valor en el uso de la información por agentes internos y externos a las organizaciones públicas.

De este modo, la gestión del conocimiento supone dar un paso más en el tratamiento informativo de las instituciones, y es el resultado de conseguir un sistema integral de información, a través del cual se constituyan procesos automatizados y normalizados en la recogida y almacenamiento de los datos.

La gestión del conocimiento se centra en saber aplicar esa información tratada para, con ayuda del contexto y de la experiencia, resolver otros problemas sociales. Es decir, ya no se trata tanto de la cantidad de información que consigan reunir y almacenar las organizaciones públicas, sino que se trata de avanzar en el uso que hagan de ella otros actores para adoptar decisiones cualificadas y aumentar así el rendimiento que extraiga de los datos públicos.

Este paso de la transferencia a la transacción, de la gestión de la información a la gestión del conocimiento, del acceso a la reutilización analizado desde la dinámica de las relaciones interadministrativas, se justifica en conocer cómo 
se producen y cómo deben modificarse dichas relaciones para mejorar la gestión y la explotación de la información pública.

Según la Real Academia de la Lengua Española, la Gobernanza es el "arte o manera de gobernar que se propone como objetivo el logro de un desarrollo económico, social e institucional duradero, promoviendo un sano equilibrio entre el Estado, la sociedad y el mercado de la economía". La Gobernanza supone reflexionar sobre el papel del estado, de la sociedad y del mercado en la realidad del momento (Cerrillo i Martínez, 2006), sin que ésta sea un objetivo en sí misma sino una forma de gestión que media para conseguir el progreso y la estabilidad. La información pública conecta sociedad, estado y mercado, por cuanto del cambio institucional que promueve el correcto acceso a los datos, se deriva el cambio económico que promueve la reutilización.

La manera en que interactúan los diversos agentes sociales, institucionales y económicos, la actuación simultánea y dialéctica de éstos de forma integrada y coordinada, es lo que puede asegurar una correcta transferencia, y posterior transacción, de los activos de la información pública. Tal arte o manera de gobernar que se propone, analizado desde el derecho a la información puede lograr, sin duda, un desarrollo económico, social e institucional duradero.

\section{CONCLUSIONES}

Primera. - La transparencia es la luz con que se ilumina el poder público, la lupa o el espejo en el que se ve y engrandece a la vista del ciudadano la acción de sus instituciones. Un principio de tal dimensión social y con un campo de actuación tan extenso, debe ser capaz de colmar toda pretensión ciudadana en democracia. La transparencia, exigible y predicable de cualquier centro de poder público, acerca el hecho político al pueblo, devolviendo en ellos el favor de su confianza prestada.

La transparencia irrumpe ahora con fuerza en el ámbito público haciendo que las instituciones mantengan vivo su cometido social y que los ciudadanos tengan presente su papel de protagonista en el sistema político.

La manifestación más característica de la transparencia, como principio vertebrador de los estados de bienestar, es el derecho a la información, en términos generales y a la información pública, de manera concreta. Unido a ello, los ciudadanos, tienen reconocido, en su estatuto subjetivo de derechos, las facultades fundamentales de recibir y de investigar información o, lo que es lo mismo, de acceder y de disponer de datos públicos. Mientras que el derecho de acceso requiere una iniciativa ciudadana de acción y una posición institucional pasiva, el derecho de recibir información precisa de una iniciativa ciudadana de reacción y una posición institucional activa para su difusión.

Por ello, en materia de información, el acceso constituye un derecho de libertad personal y la disposición un derecho prestacional de carácter colectivo.

Segunda. - La información pública es la pieza fundamental del engranaje político y el elemento vertebrador de nuestra existencia en colectividad. Por eso, la información que manejan las organizaciones y, especialmente la administración pública, constituye uno de los elementos que mayor trascendencia originan en cualquier sistema institucional, un bien común que debe compartirse por todos, un derecho básico en democracia. La información no instituye poder, toda vez que éste, por su naturaleza, debe ser informante e informado. La información orienta el ejercicio del poder y legitima la actividad de las instituciones. 
El Valor de la Información Pública en Democracia:

Aportes Teóricos para Definir una Política de Reutilización

de Datos que Impulse la Economía del Bienestar en Honduras

Por ello, tan importante mencionar que las instituciones del país desarrollen sistemas integrales de información que sirvan para procesarla, automatizarla y normalizarla, como igual de necesario se considera en la actualidad, que éstas aumenten el rendimiento de los datos tratados para fomentar nuevas finalidades que ayuden a los ciudadanos a adoptar decisiones cualificadas y a resolver problemas socioeconómicos. Persisten imprecisiones $\mathrm{y}$ lagunas en la legislación del país que es preciso clarificar.

Tercera. - La reutilización de la información generada por las instituciones constituye una de las actividades de mayor impacto social en la realidad social del momento, ya que es una fuente de primer orden en el desarrollo económico de cualquier estado. Tales instituciones realizan una labor de vital importancia para el desarrollo de la política de reutilización, ya que son quienes crean, recogen, tratan, almacenan y difunden información a mayor escala en Honduras.

Esta información tiene gran interés para dos tipos de actores: a) para las propias entidades públicas, al crear nodos de interoperabilidad administrativa en los que las organizaciones intercambian los datos que poseen $\mathrm{y}$ ofrecen así servicios al ciudadano de más calidad; y b) para entidades privadas, al optimizar recursos y facilitar la actividad profesional de éstas. La reutilización de la información pública aporta valor a los datos recogidos para una finalidad concreta, multiplicando su funcionalidad para la consecución de otros intereses públicos y privados. Es preciso que Honduras aborde la regulación de esta política pública, no sin antes afrontar algunas modificaciones en materia de transparencia y acceso a la información. 


\section{REFERENCIAS}

ARANGUREN GONZALO, L., 2005. La participación ciudadana: posibilidades y retos. Aposta, 22, pp. 1-23.

BOBBIO, N., 1980. La democracia y el poder invisible. Barcelona: Plaza \& Janés.

BUTLER, D. E., 1964. Estudios del comportamiento político. Madrid: Tecnos.

CANALES ALIENDE, J.M., 2002. Lecciones de Gestión y Administración Pública. Alicante: Servicio de Publicaciones de la Universidad de Alicante.

CANALES ALIENDE, J.M., 2014. La Gobernanza y la Administración Pública. Introducción a la Ciencia Política. Madrid: Editorial Universitas S.A., pp. 157164.

CERRILLO I MARTINEZ, A., 2006. La información del Sector Público: del acceso a la reutilización. La reutilización de la información del Sector Público. Granada: Editorial Comares, pp. 1-24.

COBACHO LÓPEZ, A., 2014. Transparencia y poder legislativo. Régimen jurídico de la transparencia del sector público: del Derecho de acceso a la reutilización de la información. Madrid: Aranzadi, pp. 135-158.

COTINO HUESO, L., 2014. El «día después» de la Ley de transparencia. Revista Jurídica de Castilla y León, 33.

GUNNARSSON, C., 1991. What is New and What is Institutional en the New Institutional Economics? Escandinavian Economic History Review, 39, pp. 43-67.

JOHNSON, N., 1975. The place of institutions in the study of politics. Political Studies Review, (23)2 y 3, pp. 271-283.

LEFTWICH, A., 1984. What is Politics? The Activity and its Study. Oxford: Basil Blackwell.

MEJIA RIVERA, J.A. y MENJÍVAR ROSALES, O., 2015. Democracia, protesta social y movilizaciones de las antorchas. Revista Envío-Honduras, 45, pp. 28-33.

NORTH, D. C., 1993. Instituciones, cambio institucional y desempeño económico. México: Fondo de Cultura Económica.

OSTROM, V., 1974. The intellectual Crisis in American Public Administration. Alabama: The University Alabama Press.

RAMOS MUSLERA, E.A., 2015. Paz Transformadora (y Participativa). Teoría y método de la paz y el conflicto desde la perspectiva sociopráxica. Tegucigalpa: Instituto Universitario en Democracia, Paz y Seguridad.

RAMOS SIMÓN, L. F.; MENDO CARMONA, C.; Y ARQUERO AVILÉS, R., 2009. La producción informativa y documental del Estado: hacia un inventario de los recursos públicos. Revista Española de Documentación Científica, 32(1), pp. 40-59.

SALOMÓN, L., 1998. El Buen Gobierno: el caso de Honduras. Tegucigalpa: Centro de Documentación de Honduras.

VALLÉS CASADEVALL, J. M., 2000. Ciencia Política. Una introducción. Barcelona: Editorial Ariel.

VILLORIA MENDIETA, M., 2010. La democratización de la Administración Pública: marco teórico. Gobernanza democrática y fiscalidad. Madrid: Tecnos, pp. 87-118. 